\title{
Correction to: Nanomedicines: current status and future perspectives in aspect of drug delivery and pharmacokinetics
}

\author{
Young Hee Choi ${ }^{1}\left[\right.$ ] Hyo-Kyung Han ${ }^{1}$
}

Published online: 5 November 2018

(c) The Author(s) 2018

\section{Correction to: \\ Journal of Pharmaceutical Investigation (2018) 48:43-60 https://doi.org/10.1007/s40005-017-0370-4}

The article "Nanomedicines: current status and future perspectives in aspect of drug delivery and pharmacokinetics", written by Young Hee Choi and Hyo-Kyung Han, was originally published electronically on the publisher's internet portal (currently SpringerLink) on 28 November 2017 without open access.

With the authors' decision to opt for Open Choice the copyright of the article changed on 5 November 2018 to () The Author(s) 2017 and the article is forthwith distributed under the terms of the Creative Commons Attribution 4.0 International License (http://creativecommons.org/licenses/ by/4.0/), which permits use, duplication, adaptation, distribution and reproduction in any medium or format, as long as you give appropriate credit to the original author(s) and the source, provide a link to the Creative Commons license and indicate if changes were made.
The original article can be found online at https://doi.org/10.1007/ s40005-017-0370-4.

Young Hee Choi

choiyh@dongguk.edu

1 College of Pharmacy and Integrated Research Institute for Drug Development, Dongguk University-Seoul, 32 Dongguk-lo, Ilsandong-gu, Goyang, Gyonggi-do 10326, Republic of Korea 